\title{
Fixed point results for the $\alpha$-Meir-Keeler contraction on partial Hausdorff metric spaces
}

\author{
Chi-Ming Chen ${ }^{1}$ and Erdal Karapınar ${ }^{2^{*}}$
}

\section{"Correspondence:}

erdalkarapinar@yahoo.com;

ekarapinar@atilim.edu.tr

${ }^{2}$ Department of Mathematics,

Atilim University, Incek, Ankara 06836, Turkey

Full list of author information is available at the end of the article

\begin{abstract}
The purpose of this paper is to study fixed point theorems for a multi-valued mapping satisfying the $\alpha$-Meir-Keeler contraction with respect to the partial Hausdorff metric $\mathcal{H}$ in complete partial metric spaces. Our result generalizes and extends some results in the literature.

MSC: 47H10; 54C60; 54H25; 55M2O

Keywords: fixed point; $\alpha$-Meir-Keeler contraction; partial metric space; partial Hausdorff metric space
\end{abstract}

\section{Introduction and preliminaries}

Fixed point theory is one of the most crucial tools in nonlinear functional analysis, and it has application in distinct branches of mathematics and in various sciences, such as economics, engineering and computer science. The most impressed fixed point result was given by Banach [1] in 1922. He concluded that each contraction has a unique fixed point in the complete metric space. Since then, this pioneer work has been generalized and extended in different abstract spaces. One of the interesting generalization of Banach fixed point theorem was given by Matthews [2] in 1994. In this remarkable paper, the author introduced the following notion of partial metric spaces and proved the Banach fixed point theorem in the context of complete partial metric space.

For the sake of completeness, we recall basic definitions and fundamental results from the literature.

Throughout this paper, by $\mathbb{R}^{+}$, we denote the set of all nonnegative real numbers, while $\mathbb{N}$ is the set of all natural numbers.

Definition 1 [2] A partial metric on a nonempty set $X$ is a function $p: X \times X \rightarrow \mathbb{R}^{+}$such that for all $x, y, z \in X$

$\left(\mathrm{p}_{1}\right) x=y$ if and only if $p(x, x)=p(x, y)=p(y, y)$;

$\left(\mathrm{p}_{2}\right) p(x, x) \leq p(x, y)$;

( $\left.\mathrm{p}_{3}\right) p(x, y)=p(y, x)$;

$\left(\mathrm{p}_{4}\right) p(x, y) \leq p(x, z)+p(z, y)-p(z, z)$.

A partial metric space is a pair $(X, p)$ such that $X$ is a nonempty set, and $p$ is a partial metric on $X$.

(0) 2013 Chen and Karapınar; licensee Springer. This is an Open Access article distributed under the terms of the Creative Commons Attribution License (http://creativecommons.org/licenses/by/2.0), which permits unrestricted use, distribution, and reproduction in any medium, provided the original work is properly cited. 
Remark 1 It is clear that if $p(x, y)=0$, then from $\left(\mathrm{p}_{1}\right)$ and $\left(\mathrm{p}_{2}\right)$, we have $x=y$. But if $x=y$, the expression $p(x, y)$ may not be 0 .

Each partial metric $p$ on $X$ generates a $\mathcal{T}_{0}$ topology $\tau_{p}$ on $X$, which has as a base the family of open $p$-balls $\left\{B_{p}(x, \gamma): x \in X, \gamma>0\right\}$, where $B_{p}(x, \gamma)=\{y \in X: p(x, y)<p(x, x)+\gamma\}$ for all $x \in X$ and $\gamma>0$. If $p$ is a partial metric on $X$, then the function $d_{p}: X \times X \rightarrow \mathbb{R}^{+}$given by

$$
d_{p}(x, y)=2 p(x, y)-p(x, x)-p(y, y)
$$

is a metric on $X$.

We recall some definitions of a partial metric space, as follows.

Definition 2 [2] Let $(X, p)$ be a partial metric space. Then

(1) a sequence $\left\{x_{n}\right\}$ in a partial metric space $(X, p)$ converges to $x \in X$ if and only if $p(x, x)=\lim _{n \rightarrow \infty} p\left(x, x_{n}\right)$;

(2) a sequence $\left\{x_{n}\right\}$ in a partial metric space $(X, p)$ is called a Cauchy sequence if and only if $\lim _{m, n \rightarrow \infty} p\left(x_{m}, x_{n}\right)$ exists (and is finite);

(3) a partial metric space $(X, p)$ is said to be complete if every Cauchy sequence $\left\{x_{n}\right\}$ in $X$ converges, with respect to $\tau_{p}$, to a point $x \in X$ such that $p(x, x)=\lim _{m, n \rightarrow \infty} p\left(x_{m}, x_{n}\right)$;

(4) a subset $A$ of a partial metric space $(X, p)$ is closed if whenever $\left\{x_{n}\right\}$ is a sequence in $A$ such that $\left\{x_{n}\right\}$ converges to some $x \in X$, then $x \in A$.

Remark 2 The limit in a partial metric space is not unique.

\section{Lemma $1[2,3]$}

(1) $\left\{x_{n}\right\}$ is a Cauchy sequence in a partial metric space $(X, p)$ if and only if it is a Cauchy sequence in the metric space $\left(X, d_{p}\right)$;

(2) a partial metric space $(X, p)$ is complete if and only if the metric space $\left(X, d_{p}\right)$ is complete. Furthermore, $\lim _{n \rightarrow \infty} d_{p}\left(x_{n}, x\right)=0$ if and only if $p(x, x)=\lim _{n \rightarrow \infty} p\left(x_{n}, x\right)=\lim _{n \rightarrow \infty} p\left(x_{n}, x_{m}\right)$.

Recently, fixed point theory has developed rapidly on partial metric spaces, see, e.g., [312] and the reference therein. Very recently, Haghi et al. [13] proved that some fixed point results in partial metric space results are equivalent to the results in the context of a usual metric space. On the other hand, this case is not valid for our main results, that is, the recent result of Haghi et al. [13] is not applicable to the main theorems.

Let $(X, d)$ be a metric space, and let $C B(X)$ denote the collection of all nonempty, closed and bounded subsets of $X$. For $A, B \in C B(X)$, we define

$$
\mathcal{H}(A, B):=\max \left\{\sup _{a \in A} d(a, B), \sup _{b \in B} d(b, A)\right\}
$$

where $d(x, B):=\inf \{d(x, b): b \in B\}$, and it is well known that $\mathcal{H}$ is called the Hausdorff metric induced the metric $d$. A multi-valued mapping $T: X \rightarrow C B(X)$ is called a contraction if

$$
\mathcal{H}(T x, T y) \leq k d(x, y)
$$


for all $x, y \in X$ and $k \in[0,1)$. The study of fixed points for multi-valued contractions using the Hausdorff metric was introduced in Nadler [14].

Theorem 1 [14] Let $(X, d)$ be a complete metric space, and let $T: X \rightarrow C B(X)$ be a multivalued contraction. Then there exists $x \in X$ such that $x \in T x$.

Very recently, Aydi et al. [15] established the notion of partial Hausdorff metric $\mathcal{H}_{p}$ induced by the partial metric $p$. Let $(X, p)$ be a partial metric space, and let $C B^{p}(X)$ be the collection of all nonempty, closed and bounded subset of the partial metric space $(X, p)$. Note that closedness is taken from $\left(X, \tau_{p}\right)$, and boundedness is given as follows: $A$ is a bounded subset in $(X, p)$ if there exist $x_{0} \in X$ and $M \in \mathbb{R}$ such that for all $a \in A$, we have $a \in B_{p}\left(x_{0}, M\right)$, that is, $p\left(x_{0}, a\right)<p(a, a)+M$. For $A, B \in C B^{p}(X)$ and $x \in X$, they define

$$
\begin{aligned}
& p(x, A):=\inf \{p(x, a): a \in A\}, \\
& \delta_{p}(A, B):=\sup \{p(a, B): a \in A\}, \\
& \delta_{p}(B, A):=\sup \{p(b, A): b \in B\}, \\
& \mathcal{H}_{p}(A, B)=\max \left\{\delta_{p}(A, B), \delta_{p}(B, A)\right\} .
\end{aligned}
$$

It is immediate to get that if $p(x, A)=0$, then $d_{p}(x, A)=0$, where $d_{p}(x, A)=\inf \left\{d_{p}(x, a): a \in\right.$ A\}.

Remark 3 [15] Let $(X, p)$ be a partial metric space, and let $A$ be a nonempty subset of $X$. Then

$$
a \in \bar{A} \quad \text { if and only if } \quad p(a, A)=p(a, a) .
$$

Aydi et al. [15] also introduced the following properties of mappings $\delta_{p}: C B^{p}(X) \times$ $C B^{p}(X) \rightarrow \mathbb{R}$ and $\mathcal{H}_{p}: C B^{p}(X) \times C B^{p}(X) \rightarrow \mathbb{R}$.

Proposition $1[15]$ Let $(X, p)$ be a partial metric space. For $A, B \in C B^{p}(X)$, the following properties hold:

(1) $\delta_{p}(A, A)=\sup \{p(a, a): a \in A\}$;

(2) $\delta_{p}(A, A) \leq \delta_{p}(A, B)$

(3) $\delta_{p}(A, B)=0$ implies that $A \subset B$;

(4) $\delta_{p}(A, B) \leq \delta_{p}(A, C)+\delta_{p}(C, B)-\inf _{c \in C} p(c, c)$.

Proposition 2 [15] Let $(X, p)$ be a partial metric space. For $A, B \in C B^{p}(X)$, the following properties hold:

(1) $\mathcal{H}_{p}(A, A) \leq \mathcal{H}_{p}(A, B)$;

(2) $\mathcal{H}_{p}(A, B)=\mathcal{H}_{p}(B, A)$;

(3) $\mathcal{H}_{p}(A, B) \leq \mathcal{H}_{p}(A, C)+\mathcal{H}_{p}(C, B)-\inf _{c \in C} p(c, c)$;

(4) $\mathcal{H}_{p}(A, B)=0$ implies that $A=B$.

Aydi et al. [15] proved the following important result. 
Lemma 2 Let $(X, p)$ be a partial metric space, $A, B \in C B^{p}(X)$ and $h>1$. For any $a \in A$, there exists $b=b(a) \in B$ such that

$$
p(a, b) \leq h \mathcal{H}_{p}(A, B)
$$

In this study, we also recall the Meir-Keeler-type contraction [16] and $\alpha$-admissible [17]. In 1969, Meir and Keeler [16] introduced the following notion of Meir-Keeler-type contraction in a metric space $(X, d)$.

Definition 3 Let $(X, p)$ be a metric space, $f: X \rightarrow X$. Then $f$ is called a Meir-Keeler-type contraction whenever for each $\eta>0$, there exists $\gamma>0$ such that

$$
\eta \leq d(x, y)<\eta+\gamma \quad \Longrightarrow \quad d(f x, f y)<\eta
$$

The following definition was introduced in [17].

Definition 4 Let $f: X \rightarrow X$ be a self-mapping of a set $X$ and $\alpha: X \times X \rightarrow \mathbb{R}^{+}$. Then $f$ is called an $\alpha$-admissible if

$$
x, y \in X, \quad \alpha(x, y) \geq 1 \quad \Longrightarrow \quad \alpha(f x, f y) \geq 1 .
$$

\section{Main results}

We first introduce the following notions of a strictly $\alpha$-admissible and and an $\alpha$-MeirKeeler contraction with respect to the partial Hausdorff metric $\mathcal{H}_{p}$.

Definition 5 Let $(X, p)$ be a partial metric space, $T: X \rightarrow C B^{p}(X)$ and $\alpha: X \times X \rightarrow$ $\mathbb{R}^{+} \backslash\{0\}$. We say that $T$ is strictly $\alpha$-admissible if

$$
\alpha(x, y)>1 \quad \text { implies that } \quad \alpha(y, z)>1, \quad x \in X, y \in T x, z \in T y .
$$

Definition 6 Let $(X, p)$ be a partial metric space and $\alpha: X \times X \rightarrow \mathbb{R}^{+} \backslash\{0\}$. We call $T$ : $X \rightarrow C B^{p}(X)$ an $\alpha$-Meir-Keeler contraction with respect to the partial Hausdorff metric $\mathcal{H}_{p}$ if the following conditions hold:

(c) $T$ is strictly $\alpha$-admissible;

$\left(\mathrm{c}_{2}\right)$ for each $\eta>0$, there exists $\gamma>0$ such that

$$
\eta \leq p(x, y)<\eta+\gamma \quad \text { implies that } \quad \alpha(x, y) \mathcal{H}_{p}(T x, T y)<\eta .
$$

Remark 4 Note that if $T: X \rightarrow C B^{p}(X)$ is a $\alpha$-Meir-Keeler contraction with respect to the partial Hausdorff metric $\mathcal{H}_{p}$, then we have that for all $x, y \in X$

$$
\alpha(x, y) \mathcal{H}_{p}(T x, T y) \leq p(x, y) .
$$

Further, if $p(x, y)=0$, then $\mathcal{H}_{p}(T x, T y)=0$. On the other hand, if $p(x, y)=0$, then $\alpha(x, y) \mathcal{H}_{p}(T x, T y)<p(x, y)$.

We now state and prove our main result. 
Theorem 2 Let $(X, p)$ be a complete partial metric space. Suppose that $T: X \rightarrow C B^{p}(X)$ is an $\alpha$-Meir-Keeler contraction with respect to the partial Hausdorff metric $\mathcal{H}$ and that there exists $x_{0} \in X$ such that $\alpha\left(x_{0}, y\right)>1$ for all $y \in T x_{0}$. Then $T$ has a fixed point in $X$ (that is, there exists $x^{*} \in X$ such that $\left.x^{*} \in T x^{*}\right)$.

Proof Let $x_{1} \in T x_{0}$. Since $T: X \rightarrow C B^{p}(X)$ is an $\alpha$-Meir-Keeler contraction with respect to the partial Hausdorff metric $\mathcal{H}_{p}$, by Remark 4, we have that

$$
\alpha\left(x_{0}, x_{1}\right) \mathcal{H}_{p}\left(T x_{0}, T x_{1}\right) \leq p\left(x_{0}, x_{1}\right) .
$$

Put $\alpha\left(x_{0}, x_{1}\right)=k_{0}>1$, and let $x_{2} \in T x_{1}$. From Lemma 2 with $h=\sqrt{k_{0}}$, we have that

$$
p\left(x_{1}, x_{2}\right) \leq \sqrt{k_{0}} \mathcal{H}_{p}\left(T x_{0}, T x_{1}\right) .
$$

Using (1) and (2), we obtain

$$
p\left(x_{1}, x_{2}\right) \leq \frac{1}{\sqrt{k_{0}}} p\left(x_{0}, x_{1}\right) .
$$

So, we can obtain a sequence $x_{n} \in X$ recursively as follows:

$$
x_{n} \in T x_{n-1} \quad \text { for all } n \in \mathbb{N} \text {. }
$$

Since $T$ is strictly $\alpha$-admissible, we deduce that $\alpha\left(x_{1}, x_{2}\right)=k_{1}>1$. Continuing this process, we have that

$$
\alpha\left(x_{n}, x_{n+1}\right)=k_{n}>1 \quad \text { for all } n \in \mathbb{N} \cup\{0\} .
$$

Since $T: X \rightarrow C B^{p}(X)$ is an $\alpha$-Meir-Keeler contraction with respect to the partial Hausdorff metric $\mathcal{H}_{p}$, by Remark 4 , we have that

$$
\alpha\left(x_{n}, x_{n+1}\right) \mathcal{H}_{p}\left(T x_{n}, T x_{n+1}\right) \leq p\left(x_{n}, x_{n+1}\right) \quad \text { for all } n \in \mathbb{N} \cup\{0\} .
$$

From Lemma 2 with $h=\sqrt{k_{n}}$, we have that

$$
p\left(x_{n+1}, x_{n+2}\right) \leq \sqrt{k_{n}} \mathcal{H}_{p}\left(T x_{n}, T x_{n+1}\right), \quad n \in \mathbb{N} \cup\{0\} .
$$

Using (5) and (6), we obtain

$$
p\left(x_{n+1}, x_{n+2}\right) \leq \frac{1}{\sqrt{k_{n}}} p\left(x_{n}, x_{n+1}\right), \quad n \in \mathbb{N} \cup\{0\} .
$$

Now, from (7) and by the mathematical induction, we obtain

$$
\begin{aligned}
p\left(x_{n+1}, x_{n+2}\right) & \leq \frac{1}{\sqrt{k_{n}}} p\left(x_{n}, x_{n+1}\right) \\
& \leq \frac{1}{\sqrt{k_{n}}} \frac{1}{\sqrt{k_{n-1}}} p\left(x_{n-1}, x_{n}\right)
\end{aligned}
$$




$$
\begin{aligned}
& \leq \cdots \\
& \leq \frac{1}{\sqrt{k_{n}}} \frac{1}{\sqrt{k_{n-1}}} \cdots \frac{1}{\sqrt{k_{0}}} p\left(x_{0}, x_{1}\right) .
\end{aligned}
$$

Since $k_{n}>1$ for all $n \in \mathbb{N} \cup\{0\}$, we get

$$
\frac{1}{\sqrt{k_{n}}}<1 \quad \text { for all } n \in \mathbb{N} \cup\{0\} \text {. }
$$

Put

$$
\bar{k}=\max \left\{\frac{1}{\sqrt{k_{n}}}: n \in \mathbb{N} \cup\{0\}\right\} .
$$

Using (8) and (9), we obtain

$$
p\left(x_{n+1}, x_{n+2}\right) \leq(\bar{k})^{n+1} p\left(x_{0}, x_{1}\right) \quad \text { for all } n \in \mathbb{N} \cup\{0\} .
$$

Letting $n \rightarrow \infty$ in (10). Then

$$
\lim _{n \rightarrow \infty} p\left(x_{n}, x_{n+1}\right)=0
$$

By the property $\left(\mathrm{p}_{2}\right)$ of a partial metric and using (11), we have

$$
\lim _{n \rightarrow \infty} p\left(x_{n}, x_{n}\right)=0
$$

Using (10) and the property $\left(\mathrm{p}_{4}\right)$ of a partial metric, for any $m \in \mathbb{N}$, we have

$$
\begin{aligned}
p\left(x_{n}, x_{n+m}\right) & \leq \sum_{i=1}^{m} p\left(x_{n+i-1}, x_{n+i}\right)-\sum_{i=1}^{m-1} p\left(x_{n+i}, x_{n+i}\right) \\
& \leq \sum_{i=1}^{m}(\bar{k})^{n+i-1} p\left(x_{0}, x_{1}\right)-\sum_{i=1}^{m-1} p\left(x_{n+i}, x_{n+i}\right) \\
& \leq \frac{(\bar{k})^{n}}{(1-\bar{k})} p\left(x_{0}, x_{1}\right)-\sum_{i=1}^{m-1} p\left(x_{n+i}, x_{n+i}\right) .
\end{aligned}
$$

Using (12) and (13), we get

$$
\lim _{n \rightarrow \infty} p\left(x_{n}, x_{n+m}\right)=0
$$

By the definition of $d_{p}$, we get that for any $m \in \mathbb{N}$,

$$
\lim _{n \rightarrow \infty} d_{p}\left(x_{n}, x_{n+m}\right) \leq \lim _{n \rightarrow \infty} 2 p\left(x_{n}, x_{n+m}\right)=0 .
$$

This yields that $\left\{x_{n}\right\}$ is a Cauchy sequence in $\left(X, d_{p}\right)$. Since $(X, p)$ is complete, from Lemma $1,\left(X, d_{p}\right)$ is a complete metric space. Therefore, $\left\{x_{n}\right\}$ converges to some $x^{*} \in X$ with respect to the metric $d_{p}$, and we also have

$$
p\left(x^{*}, x^{*}\right)=\lim _{n \rightarrow \infty} p\left(x_{n}, x^{*}\right)=\lim _{n \rightarrow \infty} p\left(x_{n}, x_{m}\right)=0 .
$$


Since $T: X \rightarrow C B^{p}(X)$ is an $\alpha$-Meir-Keeler contraction with respect to the partial Hausdorff metric $\mathcal{H}$, by Remark 4, we have that

$$
\alpha\left(x_{n}, x^{*}\right) \mathcal{H}_{p}\left(T x_{n}, T x^{*}\right) \leq p\left(x_{n}, x^{*}\right) .
$$

By the definition of the mapping $\alpha$, we have that $\alpha\left(x_{n}, x^{*}\right)>0$. Using (15), we get

$$
\lim _{n \rightarrow \infty} \mathcal{H}_{p}\left(T x_{n}, T x^{*}\right)=0
$$

Now $x_{n+1} \in T x_{n}$ gives that

$$
p\left(x_{n+1}, T x^{*}\right) \leq \delta_{p}\left(T x_{n}, T x^{*}\right) \leq \mathcal{H}_{p}\left(T x_{n}, T x^{*}\right) .
$$

Using (16), we get

$$
\lim _{n \rightarrow \infty} p\left(x_{n+1}, T x^{*}\right)=0
$$

By the property $\left(\mathrm{p}_{4}\right)$ of a partial metric, we have

$$
p\left(x^{*}, T x^{*}\right) \leq p\left(x^{*}, x_{n+1}\right)+p\left(x_{n+1}, T x^{*}\right)-p\left(x_{n+1}, x_{n+1}\right),
$$

Taking limit as $n \rightarrow \infty$, and using (12), (15) and (17), we obtain

$$
p\left(x^{*}, T x^{*}\right)=0 .
$$

Therefore, from (15), $p\left(x^{*}, x^{*}\right)=0$, we obtain

$$
p\left(x^{*}, x^{*}\right)=p\left(x^{*}, T x^{*}\right),
$$

which implies that $x^{*} \in T x^{*}$ by Remark 3 .

The following theorem, the main result of [15], is a consequence of Theorem 2 by taking $\alpha(x, y)=\frac{1}{k}$ for $k \in(0,1)$.

Theorem 3 [15] Let $(X, p)$ be a complete partial metric space. If $T: X \rightarrow C B^{p}(X)$ is a multi-valued mapping such that for all $x, y \in X$, we have

$$
\mathcal{H}_{p}(T x, T y) \leq k p(x, y)
$$

where $k \in(0,1)$. Then $T$ has a fixed point. 


\section{Author details}

${ }^{1}$ Department of Applied Mathematics, National Hsinchu University of Education, Hsinchu, Taiwan. ${ }^{2}$ Department of Mathematics, Atilim University, Incek, Ankara 06836, Turkey.

Received: 4 March 2013 Accepted: 8 August 2013 Published: 23 August 2013

\section{References}

1. Banach, S: Sur les opérations dans les ensembles abstraits et leur application aux équations intégrales. Fundam. Math. 3, 133-181 (1922)

2. Matthews, SG: Partial metric topology. In: Proc. 8th Summer of Conference on General Topology and Applications. Ann. New York Acad. Sci., vol. 728, pp. 183-197 (1994)

3. Oltra, S, Valero, O: Banach's fixed point theorem for partial metric spaces. Rend. Ist. Mat. Univ. Trieste, 36, 17-26 (2004)

4. Abdeljawad, T: Fixed points for generalized weakly contractive mappings in partial metric spaces. Math. Comput. Model. 54, 2923-2927 (2011)

5. Agarwal, RP, Alghamdi, MA, Shahzad, N: Fixed point theory for cyclic generalized contractions in partial metric spaces. Fixed Point Theory Appl. 2012, Article ID 40 (2012)

6. Altun, I, Erduran, A: Fixed point theorems for monotone mappings on partial metric spaces. Fixed Point Theory Appl. 2011, Article ID 508730 (2011)

7. Aydi, H: Fixed point results for weakly contractive mappings in ordered partial metric spaces. J. Adv. Math. Stud. 4(2), 1-12 (2011)

8. Aydi, H, Vetro, C, Sintunavarat, W, Kumam, P: Coincidence and fixed points for contractions and cyclical contractions in partial metric spaces. Fixed Point Theory Appl. 2012, Article ID 124 (2012)

9. Chi, KP, Karapinar, E, Thanh, TD: A generalized contraction principle in partial metric spaces. Math. Comput. Model. 55, 1673-1681 (2012)

10. Karapinar, E: Weak $\phi$-contraction on partial metric spaces. J. Comput. Anal. Appl., 14(2), 206-210 (2012)

11. Karapinar, E: Generalizations of Caristi Kirk's theorem on partial metric spaces. Fixed Point Theory Appl. 2011, Article ID 4 (2011)

12. Karapinar, E, Erhan, IM, Yıldız, UA: Fixed point theorem for cyclic maps on partial metric spaces. Appl. Math. Inf. Sci. 6 239-244 (2012)

13. Haghi, RH, Rezapour, S, Shahzad, N: Be careful on partial metric fixed point results. Topol. Appl. 160(3), 450-454 (2013)

14. Nadler, SB: Multi-valued contraction mappings. Pac. J. Math. 30, 475-488 (1969)

15. Aydi, H, Abbas, M, Vetro, C: Partial Hausdorff metric and Nadler's fixed point theorem on partial metric spaces. Topol. Appl., 159, 3234-3242 (2012)

16. Meir, A, Keeler, E: A theorem on contraction mappings. J. Math. Anal. Appl. 28, 326-329 (1969)

17. Samet, B, Vetro, C, Vetro, P: Fixed point theorems for $\alpha$ - $\psi$-contractive type mappings. Nonlinear Anal. 75, 2154-2165 (2012)

\section{Submit your manuscript to a SpringerOpen ${ }^{\circ}$ journal and benefit from:}

- Convenient online submission

Rigorous peer review

- Immediate publication on acceptance

- Open access: articles freely available online

- High visibility within the field

- Retaining the copyright to your article 